\title{
Assessment of Puppies Born from Caesarean Section with Dexmedetomidine Premedication under General Anaesthesia
}

\author{
Dikshita R. Patil*, S. Kathirvel, A. Kumaresan and M. Selvaraju \\ Veterinary College and Research Institute, Namakkal-637002, Tamil Nadu, India \\ *Corresponding author
}

\section{A B S T R A C T}

\begin{tabular}{|l|}
\hline K e y w o r d s \\
Caesarean, Apgar score, \\
Dexmedetomidine, Dogs
\end{tabular}

\section{Introduction}

Prolonged labour prior to delivery causes maternal physiologic compromise, resulting in foetal depression due to decrease in placental perfusion, hypoxemia and acidosis. Timing and preparation are extremely important for puppy survival for emergency CS (Moon and Erb, 2002). The Apgar score is designed to guide physicians in providing care to vulnerable young ones immediately after birth. The score is particularly useful in assessing clinical status of puppies (Apgar, 1953). Dexmedetomidine is a newer alpha 2 adrenergic agonist which is a potent sedative and analgesic agent. It is a pregnancy safe drug with adequate muscle relaxation. Although propofol crossed placental barrier, it is rapidly cleared from neonatal circulation and can be used successfully for caesarean section in canines (Doebeli et al., 2013).

\section{Materials and Methods}

Twelve full term dogs irrespective of breed, age and history of previous whelping were presented to the Veterinary Clinical Complex, Namakkal with a history of dystocia. All the dogs had a history of mating for more than 63 days. Physical and clinical examination was performed. Foetal heart beats were assessed by ultrasound. Radiographic examination revealed number of foetus. Vaginal examination was done with lubricated finger to assess the cervical os opening. The dogs with primary and secondary dystocia underwent medical treatment with injection of calcium intravenously and, or oxytocin in 
dextrose $25 \%$ at the dose rate of $10 \mathrm{ml} / \mathrm{kg}$ bodyweight. Dogs were divided into group I and II with 6 animals in each group. Group I dogs were premedicated with dexmedetomidine, induced with propofol and maintained under isoflurane inhalation anaesthesia. Group II dogs were directly induced with propofol without premedication. Before premedication the dogs in group I were preoxygenated for 10 minutes and dexmedetomidine was given at the dose rate of $15 \mathrm{mcg} / \mathrm{kg}$ body weight. After premedication dogs were induced with propofol at the dose rate of $5 \mathrm{mg} / \mathrm{kg}$ body weight and maintained with isoflurane anaesthesia after intubation. The cardiopulmonary parameters were recorded at every five minutes from intubation till the extubation time. Haematobiochemical parameters were collected before, during and after the caesarean section.

The neonates delivered through CS were evaluated by Apgar score and parameters like mucous membrane colour, heart rate, respiratory rate, reflex irritability, mobility, suckling reflex, vocalization, rooting and righting reflex were recorded at $5 \mathrm{~min}$ to $24 \mathrm{~h}$. Each parameter was assigned a value of zero, one or two based on their activity at $5 \mathrm{~min}$ from birth, $30 \mathrm{~min}, 60 \mathrm{~min}, 2 \mathrm{~h}$ and $24 \mathrm{~h}$. The neonates were placed on the electrical neonatal heating blanket to avoid mortality by hypothermia. The mucous membrane colour by direct visualization rated as 2 when mucous membrane was reddish indicative of adequate respiratory activity, 1 when mucous membrane was pink indicative of slight respiratory failure and 0 when mucous membranes were cyanotic or pale indicative of acute respiratory failure.

Heart rate more than 220 beats per min (bpm) was rated as 2, between 180-220 as 1 and less than 180bpmas 0 . Respiratory effort was rated as 2 when the respiratory rate was more than
15 or when clear crying was noticed, 1 when the respiratory rate was between six to fifteen or mild crying, 0 when the respiratory rate was less than 6 or no crying. Reflex irritability was not easily inducible and detectable in newborn dog, it was evaluated by gentle compression of the tip of the paw, evaluating the degree of newborn reaction. Crying and quick leg retraction was rated as 2 , weak leg retraction and no or just weak localization as 1 and no leg retraction and no vocalization as 0 . Mobility was evaluated by observing the strength spontaneous movement of the newborn. The strong movement was rated as 2 , mild movement as 1 and weak or absent attempt of movement as 0.Suckling reflex was elicited by inserting the clean tip of the smallest digit of the examiner into the mouth of the neonates to assess the suckling force (Veronesi et al., 2009). The score was rated as 2 , when strong suckling was noticed (5suckles/min), 1 when weak suckling (>3 suckles/min) and 0 when the suckling was absent (Vassalo et al., 2015).

Vocalization was rated as 2 , when an active reaction (vigorous) was noted. 1, when a feeble reaction (weak vocalization) was observed after the stimulation 0, when no vocalization and no response to stimuli were observed. (Moon and Erb, 2001). The rooting reflex was assessed by approaching the nose of the neonate with a hand shaped into a circle with a forefinger and thumb and checking whether the neonate inserted its nose into the circle. When the newborn is immediately fitting muzzle within circle it was rated as 2, when slow muzzle is fitting into the circle as 1 and when no such activity was noticed it was rated as 0 . The righting reflex of the neonate was assessed by placing newborn on its back on a soft surface and verifying that it returned to the right recumbence. The fast body repositioning was rated as 2, slow body repositioning as 1 and absent of this activity was rated as 0 . 
The neonates born immediately underwent resuscitation, prompt clearing of airways, blow drying of skin. The umbilical cord was ligated and cut $0.5 \mathrm{~cm}$ to $1 \mathrm{~cm}$ away from abdomen (Subramani et al., 2017). Post operatively the dogs were given Tab. Amoxicillin at the dose rate of $20 \mathrm{mg} / \mathrm{kg}$ and Tab. Tramadol orally at the dose rate of 2 $\mathrm{mg} / \mathrm{kg}$ for 7 days.

\section{Results and Discussion}

Out of all the 12 dogs presented all recovered successfully. Dexmedetomidine was proved to be excellent premedicant and pregnancy safe drug as it did not have any adverse effects on neonates. The anaesthetic protocol employed was proved safe and reliable. The dogs premedicated with dexmedetomidine showed more muscle relaxation, no movements during surgery, reliable sedation and adequate analgesia. Out of all the 32 neonates born in group I, the no mortality was noticed at five min and $24 \mathrm{~h}$ after birth. And out of all the neonates born in group II, mortality was two at five min. The neonates with Apgar score less than 6 at five minutes after birth were given prompt resuscitation and the score was increased to more than 10 after $30 \mathrm{~min}$. The neonates assessed with intensive care unit showed Apgar score more than 10 which included pink to reddish mucous membrane colour, heart rate more than two hundred and twenty beats per minute, higher respiratory rate more than fifteen breaths per minute, vigorous mobility, strong vocalization and suckling reflex was observed within thirty minutes from birth in all the neonates.

\begin{tabular}{|c|c|c|c|}
\hline Parameters & Score 0 & Score 1 & Score 2 \\
\hline $\begin{array}{l}\text { Mucous membrane } \\
\text { colour } \\
\text { (Appearance) }\end{array}$ & Cyanotic, pale & Pink & Reddish \\
\hline Heart rate (BPM) & $<180$ & 180 to 220 & $>220$ \\
\hline $\begin{array}{l}\text { Respiratory rate } \\
\text { (bpm) }\end{array}$ & $<6$ & 6 to 15 & $>15$ \\
\hline Reflex irritability & None & Feeble reaction & Active reaction \\
\hline Mobility & None & Feeble reaction & Active mobility \\
\hline Suckling & None & Weak & Energetic \\
\hline Vocalization & None & Mild & Vigorous \\
\hline Rooting & Absent & $\begin{array}{l}\text { Slow muzzle fitting } \\
\text { inside the circle }\end{array}$ & $\begin{array}{l}\text { Immediate fitting the } \\
\text { muzzle within the } \\
\text { circle }\end{array}$ \\
\hline Righting & $\begin{array}{l}\text { Absent (remains in } \\
\text { initial position) }\end{array}$ & $\begin{array}{l}\text { Slow body } \\
\text { repositioning }\end{array}$ & $\begin{array}{l}\text { Fast body } \\
\text { repositioning }\end{array}$ \\
\hline
\end{tabular}

\begin{tabular}{|c|c|c|c|c|c|}
\hline score & $\begin{array}{c}\text { No. of pups } \\
\text { in group I }\end{array}$ & $\begin{array}{c}\text { No of pups } \\
\text { in group II }\end{array}$ & Survival & Mortality & \multirow{2}{*}{$\chi^{2}$} \\
\hline $\mathbf{0}$ to 4 & 0 & $2(9.5)$ & 0 & $2(100.0)$ & \multirow{2}{*}{0.003} \\
\hline $\mathbf{5}$ to 9 & 0 & $4(19.0)$ & $4(7.9)$ & 0 & \\
\hline$>10$ & 32 & $15(71.5)$ & $47(92.1)$ & 0 & \\
\hline Total & 32 & 21 & 51 & 2 & \\
\hline
\end{tabular}

Significant at 0.05 level 
Int.J.Curr.Microbiol.App.Sci (2018) 7(8): 72-83
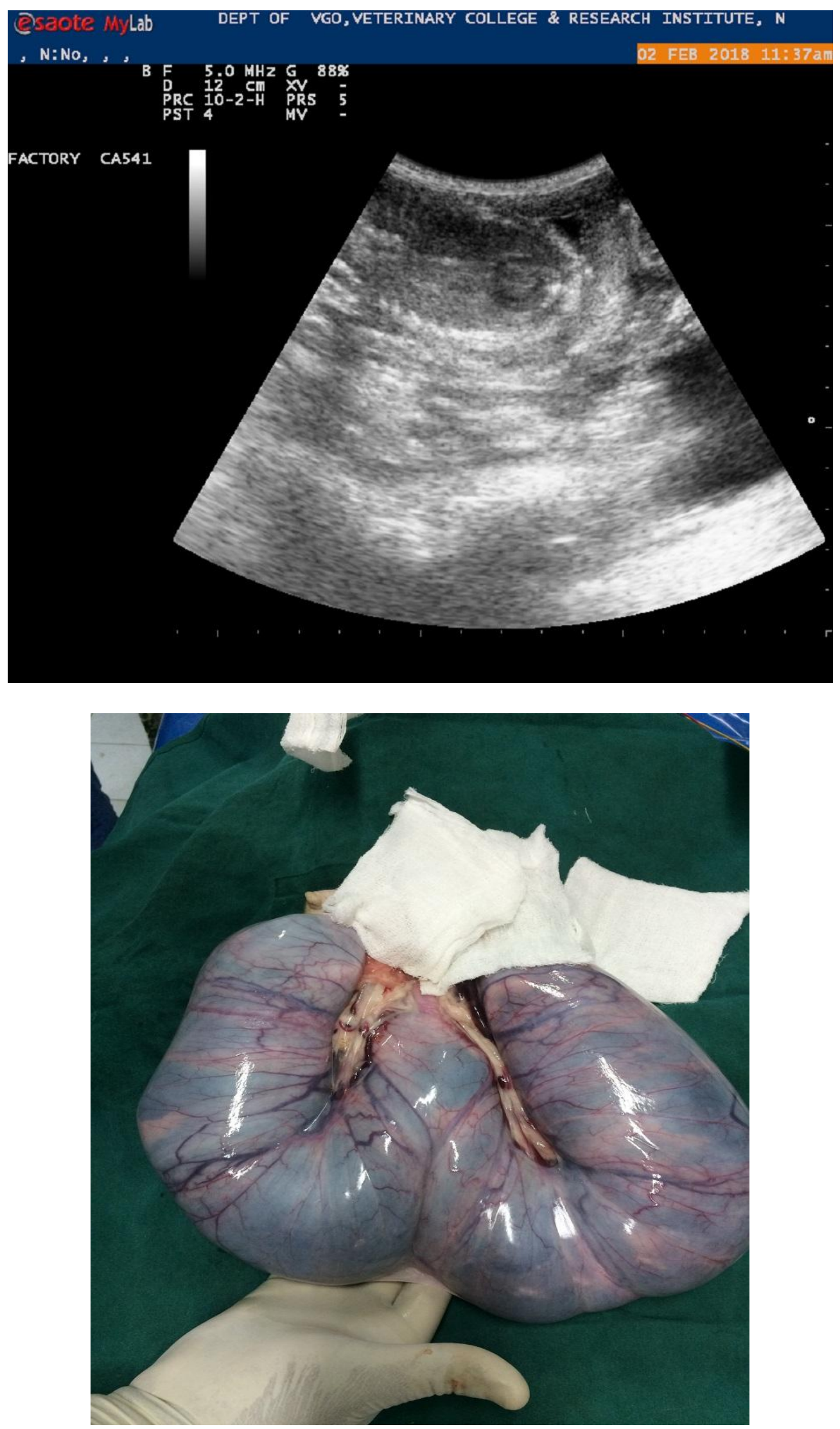


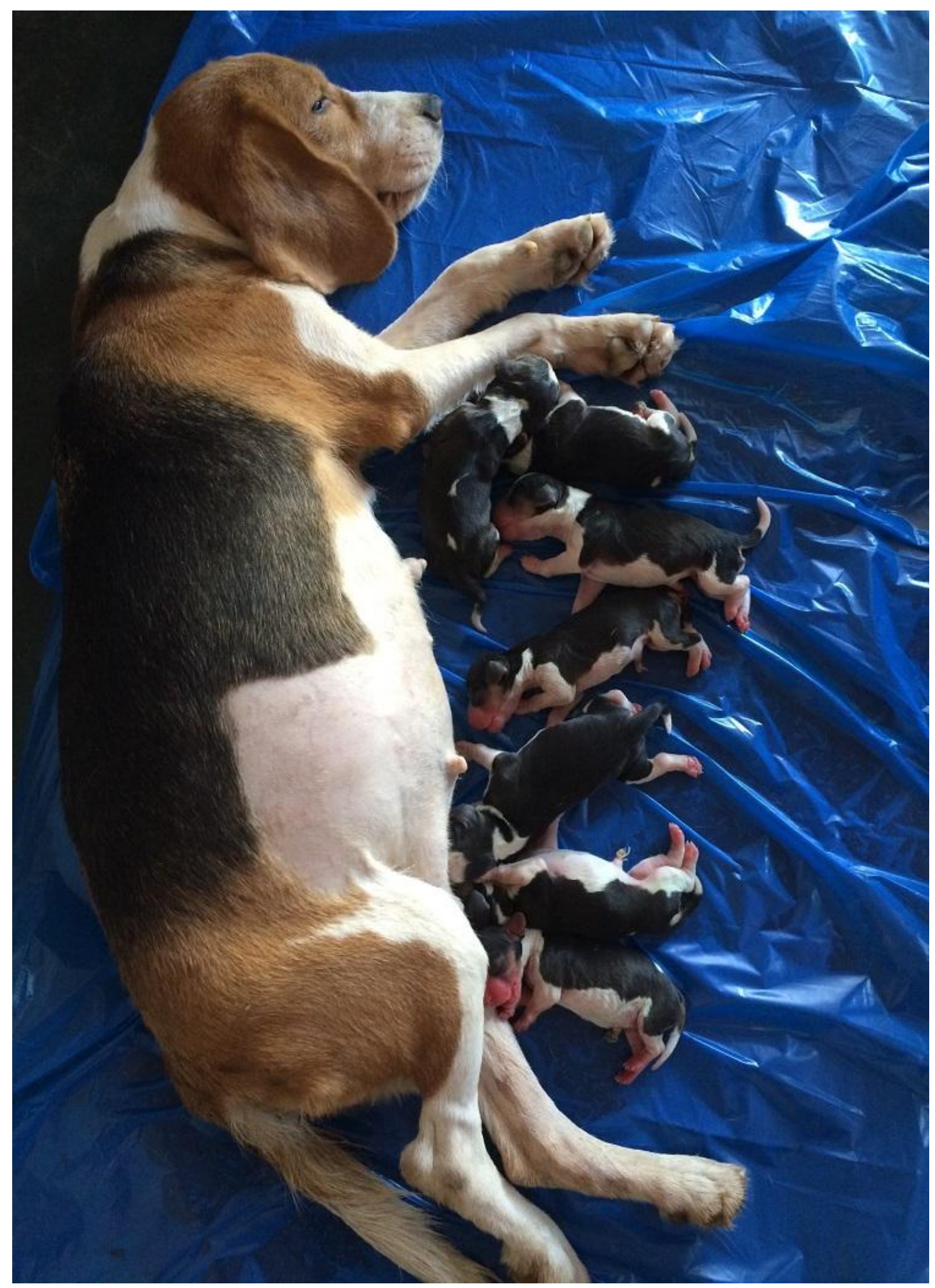


Int.J.Curr.Microbiol.App.Sci (2018) 7(8): 72-83

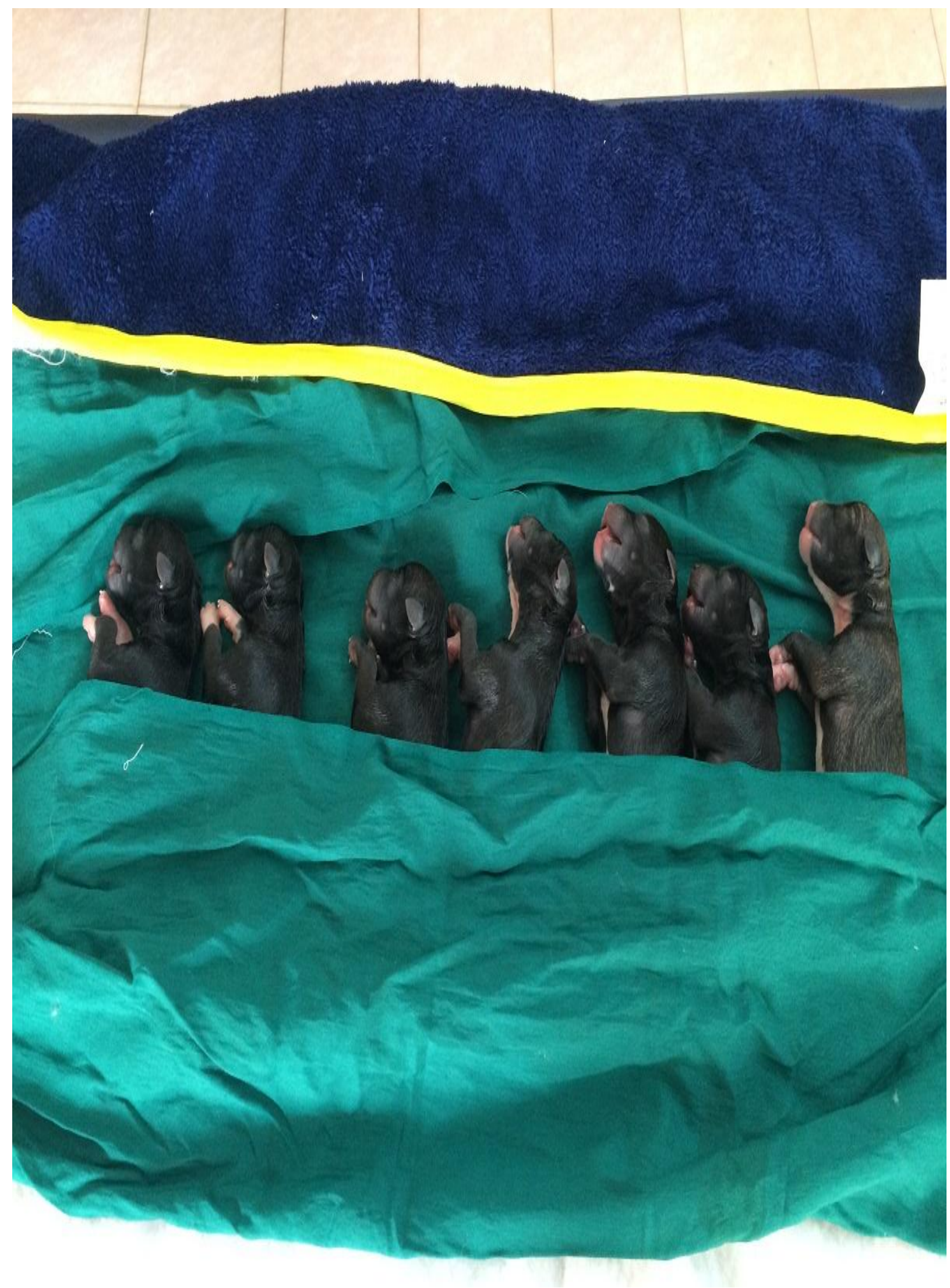


Int.J.Curr.Microbiol.App.Sci (2018) 7(8): 72-83

MMC

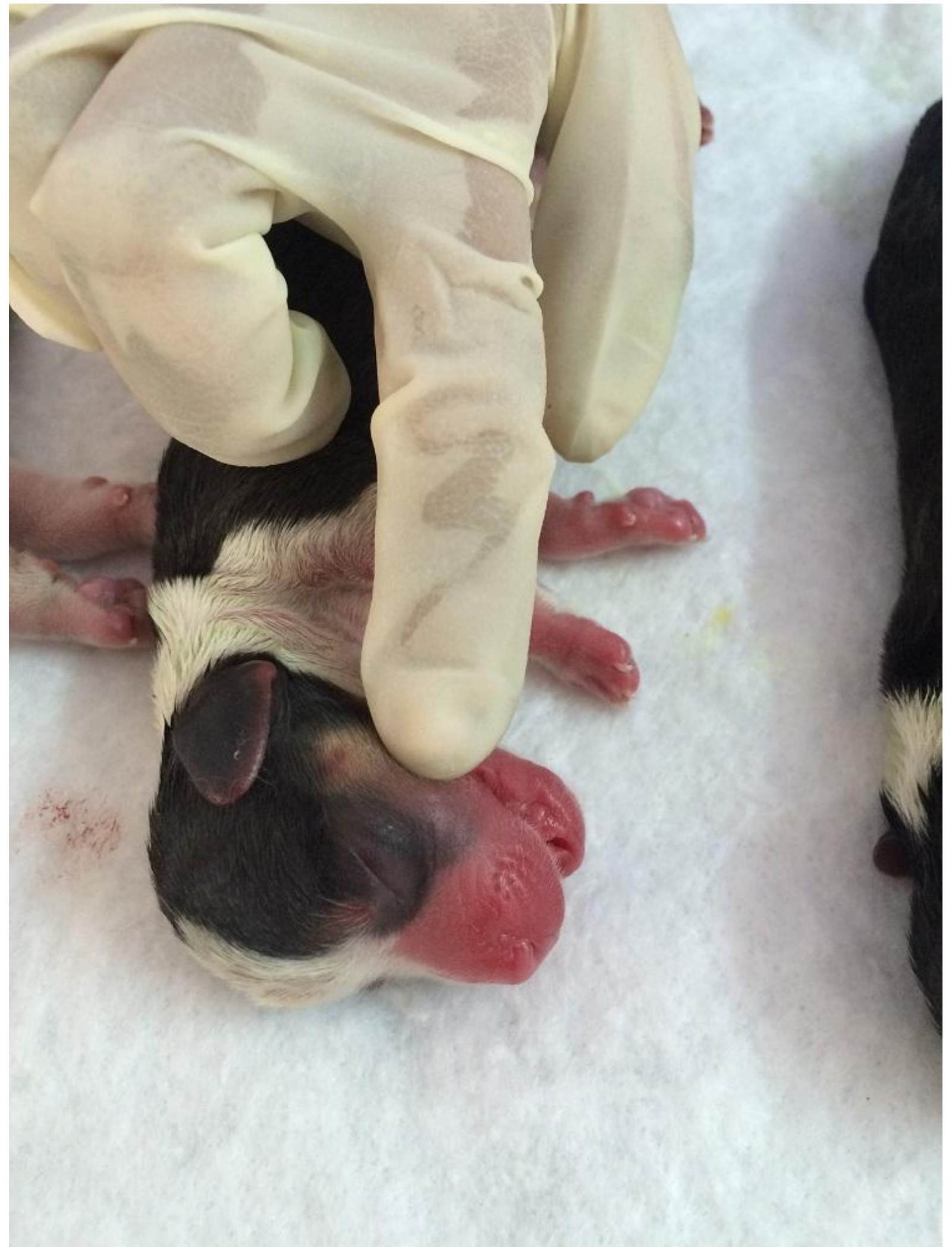


Int.J.Curr.Microbiol.App.Sci (2018) 7(8): 72-83

\section{Righthing}

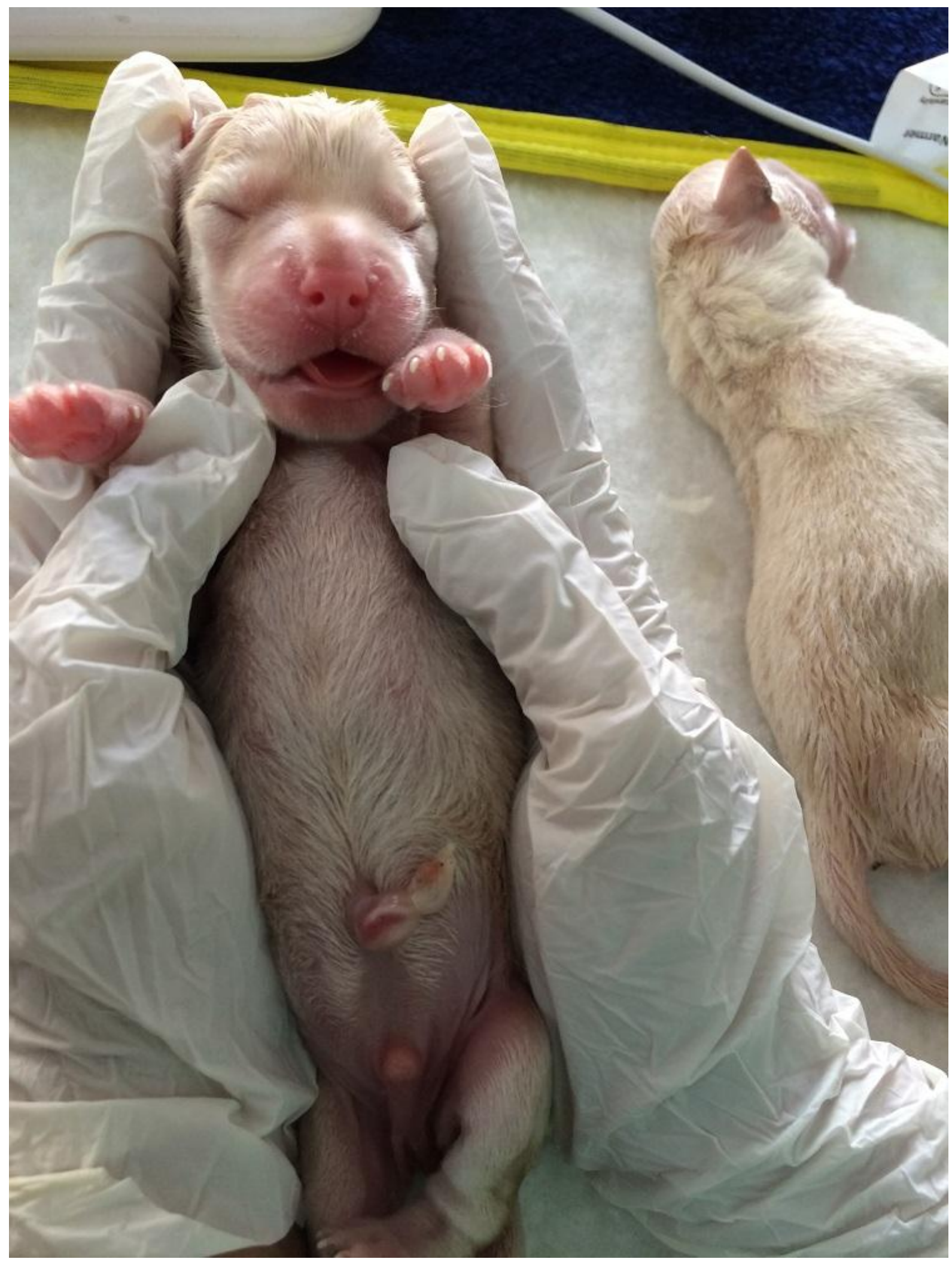


Int.J.Curr.Microbiol.App.Sci (2018) 7(8): 72-83

\section{Rooting}

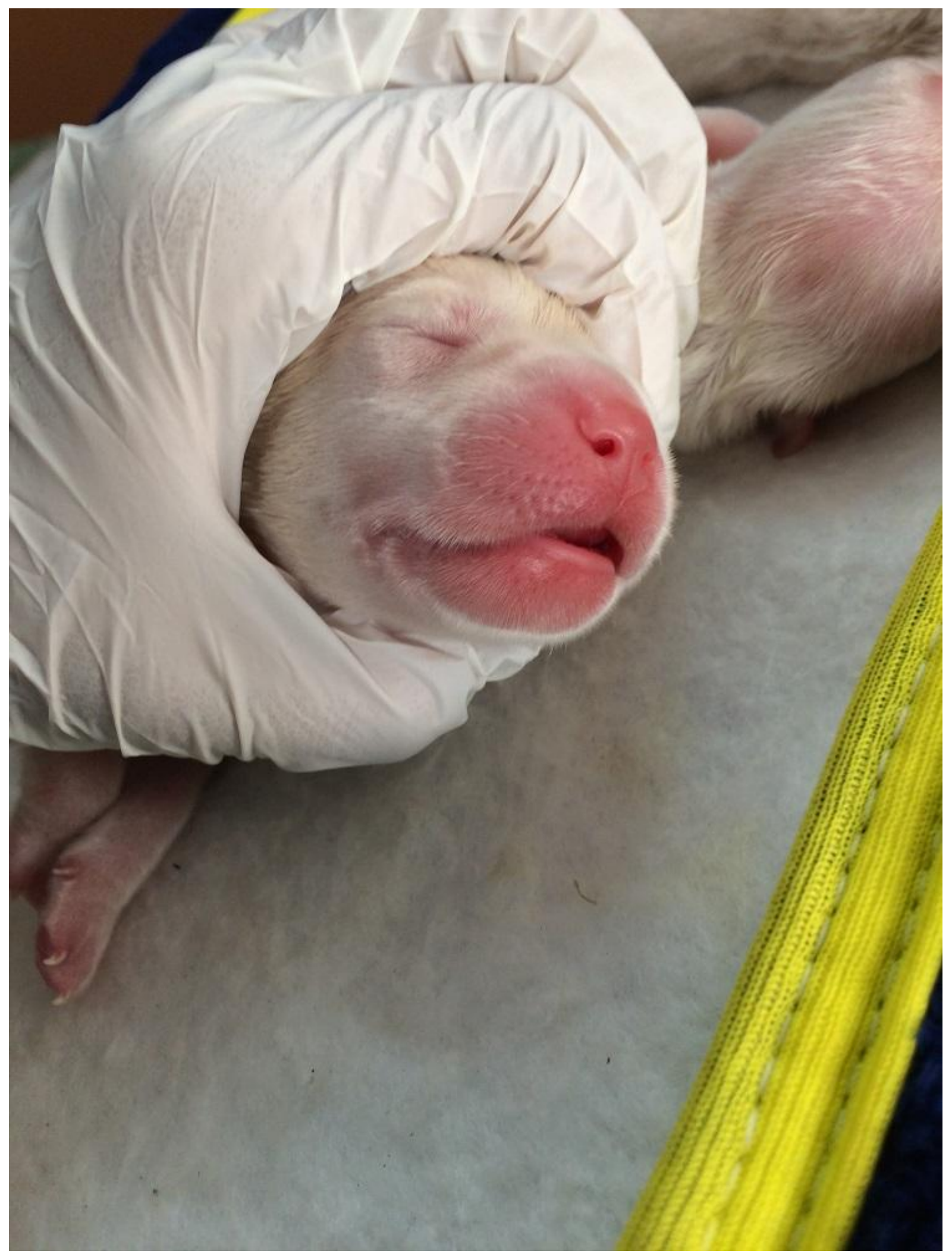


Int.J.Curr.Microbiol.App.Sci (2018) 7(8): 72-83

\section{Suckling reflex}

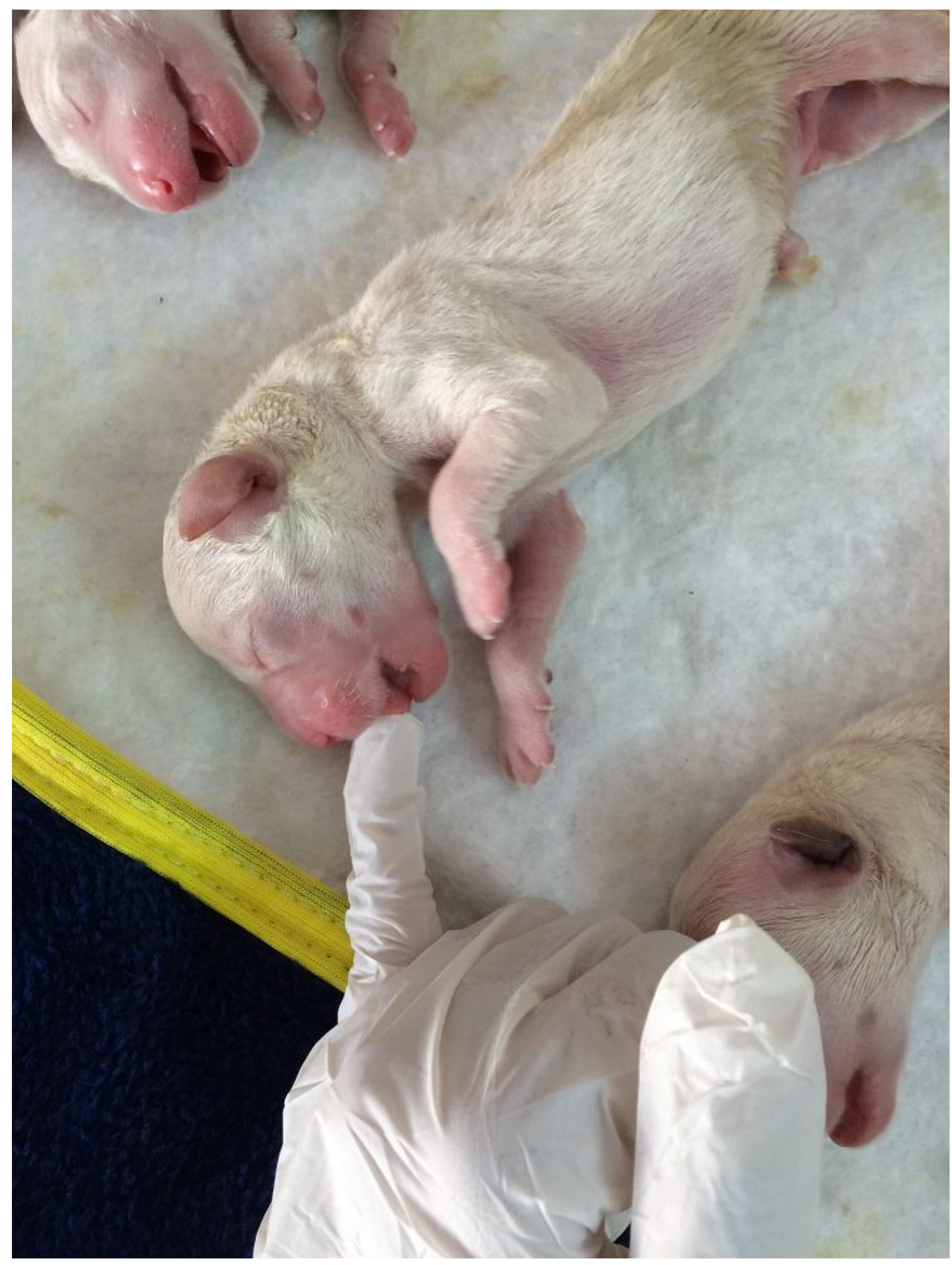




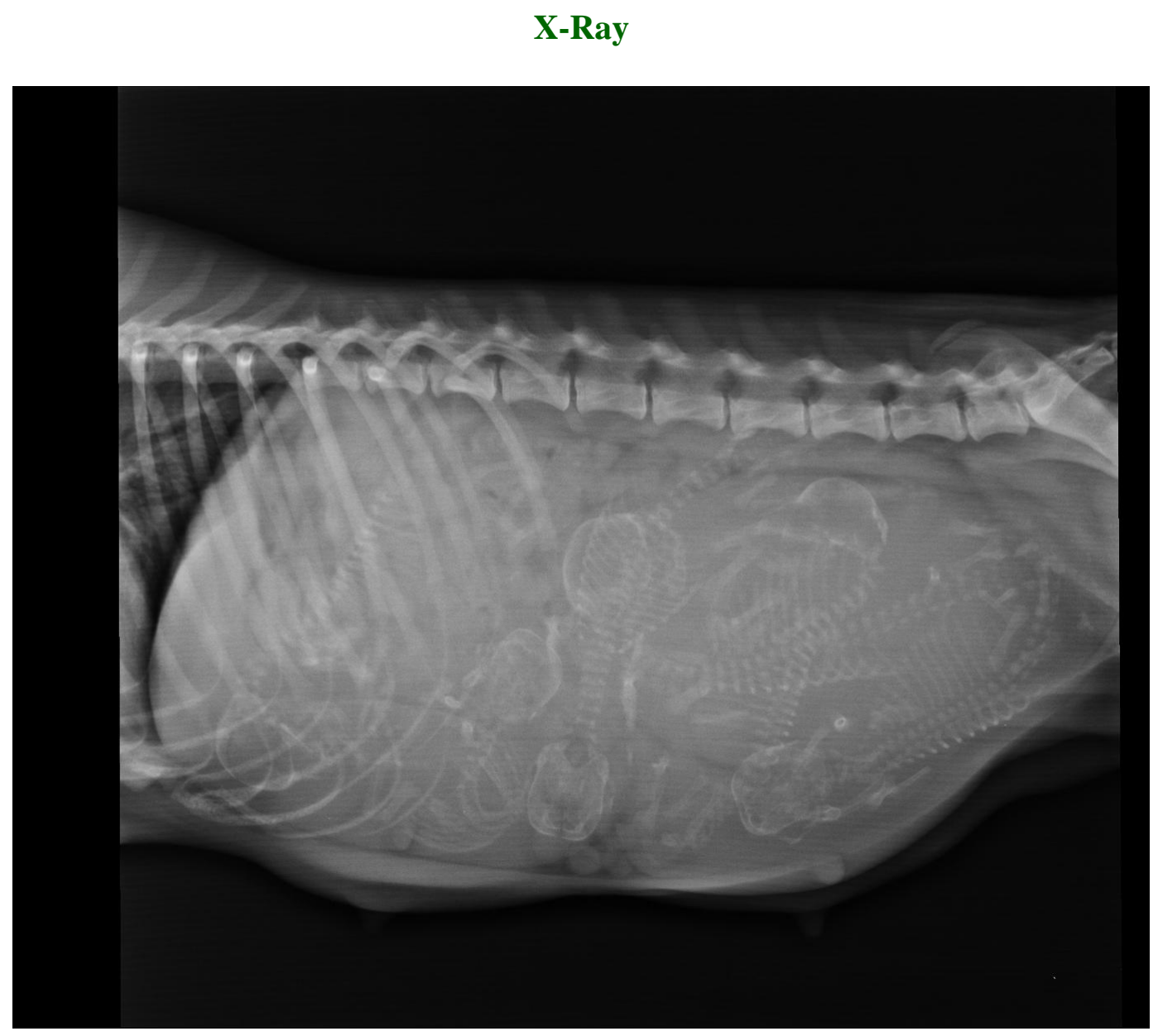

Dexmedetomidine did not produce any adverse effects on cardiopulmonary system of dam as well as neonates. Apgar score was proved easy, safe, reliable and inexpensive method for neonatal assessment.

\section{Acknowledgement}

The authors are thankful to the Dean, Veterinary College and Research Institute, Namakkal for providing facilities to carry out this research study.

\section{References}

Apgar, V. (1953). A proposal of new methods of evaluation of newborn infants. Curr. Res., 22: 142-150.

Bharatidasan, M., George, R.S., Shafiuzama, M., Kannan, T.A. and Ramesh, S.
(2016). Modified apgar score system for prediction of neonatal survival puppies delivered through caesarean section. Indian. J. Dev. Res., 6: 10281-10284.

Doebeli, A.E., Michel, E., Bettschart, R., Hartnack, S. and Reichler, L.M. (2013). Apgar score after induction of anesthesia for canine caesarean section with alfaxalone versus propofol. Theriogenology, 80: 850-854.

Groppetti, D., Pecile, A., Del. A.P., Copley, K., Minero, M. and Cremonesi, F. (2010). Evaluation of newborn canine viability by means of umbilical vein lactate measurement, apgar score and uterine

Tocodynametry. Theriogenology, 52: 272-276.

Jaykumar, C., Krishnaswamy, A., Sudha, G. and Honnappa, T.G. (2015). Assessment of canine neonate by Apgar 
scoring system and its value as an index of short term neonatal survival. Indian J. Anim. Reprod., 36: 14-20

Moon, P.F. and Erb, H.N. (2002). Perioperative factors associated with puppy vigor after delivery by caesarean section. J. Am. Anim. Hosp. Asssoc., 38: 90-96.

Subramani, A. (2017). Assessment of clinical status of newborn puppies and survival prognosis using modified apgar score system. M.V.Sc, thesis submitted to Tamil Nadu Veterinary and Animal Sciences University, Chennai.
Vassalo, F.G., Simoes, C.R., Sudano, M.J., Presters, N.C., Lopes, M.D., Chiacchio, S.B. and Lourenco, M.L. (2015). Topics in routine assessment in newborn puppy viability. Topics in Companion Animal Medicine, 30: 16-21.

Veronesi, M.C., Panzani, M., Faustani, M. and Rota, A. (2009). An Apgar scoring system for routine assessment of newborn puppy viability and short-term survival prognosis. Theriogenology, 72: 401-407.

\section{How to cite this article:}

Dikshita R. Patil, S. Kathirvel, A. Kumaresan and Selvaraju, M. 2018. Assessment of Puppies Born from Caesarean Section with Dexmedetomidine Premedication under General Anaesthesia. Int.J.Curr.Microbiol.App.Sci. 7(08): 72-83. doi: https://doi.org/10.20546/ijcmas.2018.708.009 